\title{
Deep brain stimulation for movement disorders - a history of success and challenges to conquer
}

\author{
Lars Wojtecki ${ }^{1,2 *}$, Carlo Colosimo ${ }^{3}$ and Romulo Fuentes ${ }^{4}$ \\ 1 Center for Movement Disorders and Neuromodulation, Department of Neurology, Medical Faculty, Heinrich-Heine-University Duesseldorf, Duesseldorf, Germany \\ 2 Institute of Clinical Neuroscience and Medical Psychology, Medical Faculty, Heinrich-Heine-University Duesseldorf, Duesseldorf, Germany \\ 3 Department of Neurology and Psychiatry, "Sapienza" University, Rome, Italy \\ ${ }^{4}$ Edmond and Lily Safra International Institute of Neuroscience of Natal, Natal, Brazil \\ *Correspondence:wojtecki@uni-duesseldorf.de
}

A commentary on

Deep brain stimulation for movement disorders

by Pizzolato, G., and Mandat, T. (2012). Front. Integr. Neurosci. 6:2. doi: 10.3389/ fnint.2012.00002

Up to date, tens of thousands patients have undergone implantation of deep brain stimulation electrodes - mainly for the treatment of Parkinson's disease, Essential Tremor, and Idiopathic Dystonia. Pizzolato and Mandat (2012) give a short and comprehensive review on the current status of deep brain stimulation for these movement disorders. For this special issue "The development of deep brain stimulation for neurological and psychiatric disorders: clinical, societal, and ethical issues" the reviews of Pizzolato and Mandat (2012) and of Sarem-Aslani and Mullett (2011) give an overview of the state of the art and currently approved indications for this therapy. There is no doubt, that especially in the field of movement disorders, deep brain stimulation is a history of great success in neurological therapy and a most valuable tool for research.

However, especially in the light of other articles of this special issue that deal, e.g., with ethical issues, modulation of affect, cognition, and behavior, or possible changes of personality by deep brain stimulation, there remain some major challenges and questions for the future. We will have to conquer these challenges in order to understand and improve the technique - to finally transfer it to a successful therapy for other disorders especially in the neuro-psychiatric domain.
These challenges are:

(1)To understand the natural history of the diseases and the underlying functional networks and circuits to select the best targets for neuromodulation.

Beneficial motor effects of DBS are well described, e.g., there is class one evidence for the usefulness of DBS for Parkinson's disease (Deuschl et al., 2006; Weaver et al., 2009; Williams et al., 2010). However, to determine the real value in improving quality of life we have to gain more insight into the dynamics of the diseases. What is the right time point for implantation? Current data suggest that despite stable long terms effects on motor fluctuations in $\mathrm{PD}$, we might miss the right time window in elderly patients as DBS will not manage to improve axial motor symptoms (Fasano et al., 2010b). On the other hand, prospective studies to examine the benefits of earlier implantation are still on the way. Furthermore, the interactions of disease state, operation, and implantation on cognitive side effects are not fully understood. Although there are many publications that show "on/off" effects on cognitive measurements, some data suggest that the implantation per se - and not the stimulation - might be the main cause of the decline in executive function (Okun et al., 2012). In line with this discussion we have to further study the right stimulation targets for to gain the best outcome. For example, GPI stimulation recognizes a renaissance, as it might be a cognitive safer target for some patients. In order to efficiently access and modulate the neural net- works, many findings point into the direction that fiber tracts rather than nuclei might be the right target of choice - not only in PD, but also in thalamic stimulation for essential tremor: some findings suggest that differential stimulation of fiber tracts can be crucial for modulation of distinct symptoms like tremor versus ataxia (Fasano et al., 2010a).

(2)To disentangle the mechanisms of action of deep brain stimulation.

The discussion about the effects of stimulating different fiber pathways leads to the point were we need a refined understanding of the connections and relationship between the different neural circuits involved in the desired output behavior. When it comes to STN stimulation, stimulation of afferents from cortical areas might be the main mechanism - as studies that used the optogenetic method suggest (Gradinaru et al., 2009). Additionally, volume of tissue activated studies, other functional imaging, microelectrode multi-site recordings, local field potential-, EEG-, and magnetoencephalographic studies, alone or combined, might provide guides to understand the stimulation effects on local and long range neuronal networks.

(3) To improve stimulation techniques On the basis of a better understanding of the mechanisms underlying DBS, we have to tailor new stimulation techniques. New programming options as interleaving (Wojtecki et al., 2011) and constant current devices (Okun et al., 2012) are on the market now. Furthermore, new electrodes with improved variability of stimulation 
direction will be helpful. Finally, as a result of disentangling the neuronal network codes (e.g., beta and high frequency oscillations in PD), closed-loop devices (Rouse et al., 2011), that could provide stimulation "on demand," will hopefully be a major step forward to improve these therapies.

(4) To learn from the history of DBS in movement disorders.

Especially when discussing modulation of complex behavior in patients with DBS and when we aim to increase the usage and indication of the technique, we have to learn from the lessons of the past. What was the reason for success of DBS in movement disorders? We think that there are four main points: determining the right patients with a distinct diagnosis for therapy, a detailed knowledge of the involved neural circuits, good designed and ethical clinical studies, and interdisciplinary cooperation between specialists (e.g., neurology, neurosurgery). On this basis, the future will be open for more indications and better understanding.

\section{REFERENCES}

Deuschl, G., Schade-Brittinger, C., Krack, P., Volkmann, J., Schäfer, H., Bötzel, K., Daniels, C., Deutschländer, A., Dillmann, U., Eisner, W., Gruber, D., Hamel, W., Herzog, J., Hilker, R., Klebe, S., Kloss, M., Koy, J., Krause, M., Kupsch, A., Lorenz, D., Lorenzl,
S., Mehdorn, H. M., Moringlane, J. R., Oertel, W., Pinsker, M. O., Reichmann, H., Reuss, A., Schneider, G. H., Schnitzler, A., Steude, U., Sturm, V., Timmermann, L., Tronnier, V., Trottenberg, T., Wojtecki, L., Wolf, E., Poewe, W., Voges, J., and German Parkinson Study Group, Neurostimulation Section. (2006). A randomized trial of deep-brain stimulation for Parkinson's disease. N. Engl. J. Med. $355,896-908$.

Fasano, A., Herzog, J., Raethjen, J., Rose, F. E. M., Muthuraman, M., Volkmann, J., Falk, D., Elble, R., and Deuschl, G. (2010a). Gait ataxia in essential tremor is differentially modulated by thalamic stimulation. Brain 133, 3635-3648.

Fasano, A., Romito, L. M., Daniele, A., Piano, C., Zinno, M., Bentivoglio, A. R., and Albanese, A. (2010b). Motor and cognitive outcome in patients with Parkinson's disease 8 years after subthalamic implants. Brain 133, 2664-2676.

Gradinaru, V., Mogri, M., Thompson, K. R., Henderson, J. M., and Deisseroth, K. (2009). Optical deconstruction of parkinsonian neural circuitry. Science 324 354-359.

Okun, M. S., Gallo, B.V., Mandybur, G., Jagid, J., Foote, K. D., Revilla, F. J., Alterman, R., Jankovic, J., Simpson, R., Junn, F., Verhagen, L., Arle, J. E., Ford, B., Goodman, R. R., Stewart, R. M., Horn, S., Baltuch, G. H., Kopell, B. H., Marshall, F., Peichel, D., Pahwa, R., Lyons, K. E., Tröster, A. I., Vitek, J. L., Tagliati, M., and for the SJM DBS Study Group. (2012). Subthalamic deep brain stimulation with a constant-current device in Parkinson's disease: an open-label randomised controlled trial. Lancet Neurol. 11, 140-149.

Pizzolato, G., and Mandat, T. (2012). Deep brain stimulation for movement disorders. Front. Integr. Neurosci. 6:2. doi: $10.3389 /$ fnint.2012.00002

Rouse, A. G., Stanslaski, S. R., Cong, P., Jensen, R. M., Afshar, P., Ullestad, D., Gupta, R., Molnar, G. F., Moran, D. W., and Denison, T. J. (2011). A chronic generalized bi-directional brain- machine interface. J. Neural Eng. 8, 036018. doi: 10.1088/1741-2560/8/3/036018

Sarem-Aslani, A., and Mullett, K. (2011). Industrial perspective on deep brain stimulation: history, current state, and future developments. Front. Integr. Neurosci. 5:46. doi: 10.3389/fnint.2011.00046

Weaver, F. M., Follett, K., Stern, M., Hur, K., Harris, C., Marks, W. J., Rothlind, J., Sagher, O., Reda, D., Moy, C. S., Pahwa, R., Burchiel, K., Hogarth, P., Lai, E. C., Duda, J. E., Holloway, K., Samii, A., Horn, S., Bronstein, J., Stoner, G., Heemskerk, J., Huang, G. D., and CSP 468 Study Group. (2009). Bilateral deep brain stimulation vs best medical therapy for patients with advanced Parkinson disease: a randomized controlled trial. JAMA 301, 63-73.

Williams, A., Gill, S., Varma, T., Jenkinson, C., Quinn, N., Mitchell, R., Scott, R., Ives, N., Rick, C., Daniels, J., Patel, S., Wheatley, K., and PD SURG Collaborative Group. (2010). Deep brain stimulation plus best medical therapy versus best medical therapy alone for advanced Parkinson's disease (PD SURG trial): a randomised, open-label trial. Lancet Neurol. 9, 581-591.

Wojtecki, L., Vesper, J., and Schnitzler, A. (2011). Interleaving programming of subthalamic deep brain stimulation to reduce side effects with good motor outcome in a patient with Parkinson's disease. Parkinsonism Relat. Disord. 17, 293-294.

Received: 30 January 2012; accepted: 08 February 2012; published online: 23 February 2012.

Citation: Wojtecki L, Colosimo C and Fuentes R (2012) Deep brain stimulation for movement disorders-a history of success and challenges to conquer. Front. Integr. Neurosci. 6:6. doi: 10.3389/fnint.2012.00006

Copyright $\odot 2012$ Wojtecki, Colosimo and Fuentes. This is an open-access article distributed under the terms of the Creative Commons Attribution Non Commercial License, which permits non-commercial use, distribution, and reproduction in other forums, provided the original authors and source are credited. 